\title{
Introduction of Noninvasive Prenatal Testing for Blood Group and Platelet Antigens from Cell-Free Plasma DNA Using Digital PCR
}

\author{
Marion Eryilmaz Dennis Müller Gabi Rink Harald Klüter Peter Bugert \\ Institute of Transfusion Medicine and Immunology, Heidelberg University, Medical Faculty Mannheim, \\ German Red Cross Blood Service Baden-Württemberg - Hessen, Mannheim, Germany
}

\section{Keywords}

Noninvasive prenatal testing · Digital PCR · Cell-free DNA · Blood group genotyping

\footnotetext{
Abstract

Background: Noninvasive prenatal testing (NIPT) for fetal antigens is a common standard for targeted immune prophylaxis in RhD-mediated hemolytic disease of the fetus and newborn, and is most frequently done by quantitative $P C R$ (qPCR). A similar approach is considered for other blood group and human platelet alloantigens (HPA). Because of a higher sensitivity compared to qPCR for rare molecule detection, we established and validated digital PCR (dPCR) assays for the detection of RHD exons 3, 5 and 7, KEL1, HPA-1a, and HPA-5b from cell-free DNA (cfDNA) in plasma. The dPCR assays for the Y-chromosomal marker amelogenin and autosomal SNPs were implemented as controls for the proof of fetal DNA. Methods: Validation was performed on dilution series of mixed plasma samples from volunteer donors with known genotypes. After preamplification of the target loci, two-color (FAM and VIC) TaqMan ${ }^{\mathrm{TM}}$ probe chemistry and chip-based dPCR were applied. The assays for RHD included GAPDH as an internal control. For the diallelic markers KEL1/2, HPA$1 \mathrm{a} / \mathrm{b}, \mathrm{HPA}-5 \mathrm{a} / \mathrm{b}$, and AMEL-X/Y and 3 autosomal SNPs, the probes enabled allelic discrimination in the two fluorescence channels. The dPCR protocol for NIPT was applied to plasma samples from pregnant women. Results: The RHD
}

exon 5 assay allowed the detection of a $0.05 \%$ RHD target in an RhD-negative background, whereas the exon 7 assay required at least a $0.25 \%$ target. The exon 3 assay showed the highest background and required at least a 2.5\% RHD target for reliable detection. The dPCR assays for the diallelic markers revealed similar sensitivity and enabled the detection of at least a $0.5 \%$ target allele. The HPA- 1 a assay was the most sensitive and allowed target detection in plasma mixtures containing only $0.05 \%$ HPA- 1 a. The plasma samples from 13 pregnant women at different gestational ages showed unambiguous positive and negative results for the analyzed targets. Conclusion: Analysis of cfDNA from maternal plasma using $\mathrm{dPCR}$ is suitable for the detection of fetal alleles. Because of the high sensitivity of the assays, the NIPT protocol for RhD, KEL1, and HPA can also be applied to earlier stages of pregnancy.

(c) 2019 S. Karger AG, Basel

\section{Introduction}

The immunization in pregnancy against a blood group or platelet antigen of the fetus can cause severe complications such a hemolytic disease of the fetus and newborn (HDFN) or fetal and neonatal alloimmune thrombocytopenia (FNAIT). The development of maternal alloantibodies against the RhD antigen can be circumvented by the administration of immunoglobulins. In Germany and 
other countries, anti-D prophylaxis is given to all D-negative pregnant women irrespective of the fetal $\mathrm{D}$ antigen status. Based on allele frequency, it can be estimated that about $35 \%$ of $\mathrm{D}$-negative pregnant women do not require anti-D prophylaxis because the fetus is $\mathrm{D}$ negative [1]. The use cell-free DNA (cfDNA) from maternal plasma to identify the RhD status of the unborn child is well known [2]. This noninvasive prenatal testing (NIPT) for $\mathrm{RhD}$ is established as nationwide screening in different European countries [3-5]. The standard procedure includes blood sampling in gestational week 24-27 and quantitative real-time PCR (qPCR) targeting two $R H D$ exons, i.e., exons $5+7$ or $5+10$ or $7+10$. A high sensitivity $(0.01-$ $0.09 \%$ false-negative results) and specificity $(0.1-0.9 \%$ false-positive results) of qPCR could be demonstrated. Other blood group antigens such as Rhc, RhE, and Kell (KEL1) can also cause HDFN [6]. Different NIPT methods have been developed based on qPCR or next-generation sequencing; however, none of them is implemented in a consecutive screening program [7-9].

The human platelet alloantigens (HPA) $1 \mathrm{a}$ and $5 \mathrm{~b}$ are the most common cause of FNAIT. Similar to the antibody-mediated destruction of red blood cells in HDFN, maternal alloimmunization against HPA-1a or HPA-5b leads to immune thrombocytopenia in the fetus. In contrast to the $\mathrm{RhD}$ genetics, i.e., lack of the entire $R H D$ gene in $\mathrm{RhD}$-negative individuals, a single nucleotide polymorphism (SNP) in the corresponding glycoprotein gene represents the molecular basis of the HPA- 1 and -5 antigens [10]. With regard to sensitivity and specificity, the detection of SNP alleles is much more challenging than the detection of RHD exons. Different NIPT methods using $\mathrm{qPCR}$ and next-generation sequencing have been developed, but consecutive screening of HPA-1a- and HPA-5b-negative pregnant women is not established yet [11-13]. The introduction of digital PCR (dPCR) offered significant advantages in the specific and sensitive detection of genetic markers. Compared to qPCR, a better signal-to-noise ratio results in a higher sensitivity of dPCR. Additionally, absolute quantification is possible with dPCR, without the use of standard curves. A dPCR method for the detection of RHD exons 5, 7, and 10 in cfDNA showed results comparable to those obtained with qPCR [14]. However, for rare molecule detection of SNP alleles or point mutations, $\mathrm{dPCR}$ is superior to $\mathrm{QPCR}$ [15]. $\mathrm{dPCR}$ reliably detected $0.1 \%$ rare alleles, whereas $\mathrm{qPCR}$ required at least $1 \%$ rare alleles for stable detection.

The focus of this work is the establishment and technical validation of chip-based dPCR assays for NIPT of RhD, KEL1, HPA-1a, and HPA-5b from cfDNA. Our main intension was to allow the detection of cell-free fetal DNA (cffDNA) in early pregnancy, especially in cases with maternal alloantibodies. With regard to anti-D prophylaxis, the dPCR methods can also be used for screen- ing in the second trimester. The sensitivity of the assays was evaluated using mixed plasma samples of donors with known genotypes. In addition, we introduced control assays for detection of the Y-specific allele of the gonosomal target amelogenin (AMEL) and for autosomal SNPs from the SNPforID panel [16, 17]. All assays were based on two-color (FAM and VIC) TaqMan ${ }^{\mathrm{TM}}$ technology with previously published primers and probes $[14,18,19]$ or commercial assays that have been used before in a genotyping project [20]. Finally, the validated dPCR assays were exemplarily applied to plasma samples of pregnant women and confirmed the high sensitivity and specificity for the detection of the rare (fetal) alleles.

\section{Materials and Methods}

\section{Preparation of Plasma Samples and Isolation of cfDNA}

The validation study was performed on blood samples from healthy volunteer donors (staff of the institute) after they had given their consent. The validated APCR protocol was applied to plasma samples from pregnant women who also gave informed written consent. The study protocol was approved by the local ethics committee (Vote No. 2017-665N-MA). The blood samples were stored and shipped at room temperature and processed within 3 days after sampling. Plasma was obtained from EDTA blood after centrifugation for $10 \mathrm{~min}$ at $2,000 \mathrm{~g}$, transferred to new centrifuge tubes, and centrifuged at $16,000 \mathrm{~g}$ for $10 \mathrm{~min}$ at $4^{\circ} \mathrm{C}$. Cell-free plasma was then transferred to cryotubes and stored at $-30^{\circ} \mathrm{C}$ until use.

For the sensitivity tests, we prepared dilution series ( $1 \mathrm{~mL}$ final volume each) of mixed plasma samples with $5 \%, 1 \%, 0.5 \%$, and $0.1 \%$ plasma of a donor heterozygous for the target (RHD, KEL1, HPA-1a, HPA-5b, and AMEL-Y) and 95\%, 99\%, 99.5\%, and 99.9\% plasma of a donor negative for the target, respectively. All tests were conducted with biological triplicates from different donors. Isolation of DNA from $1 \mathrm{~mL}$ cell-free plasma was conducted with the QIAmp Circulating Nucleic Acids Kit (Qiagen, Hilden, Germany) according to the manufacturer's protocol. The cfDNA was eluted from the column using $100 \mu \mathrm{L}$ sterile water, and the DNA concentration was measured photometrically (NanoDrop Lite; Thermo Fisher Scientific GmbH, Dreieich, Germany). From a total of 72 isolations, the range of cfDNA concentration was 2.1-19.5 $\mathrm{ng} / \mu \mathrm{L}(5.0 \pm 2.3)$

\section{Preamplification PCR}

In order to increase the number of evaluable signals in $\mathrm{APCR}$, all loci were preamplified by PCR using primers flanking the $\mathrm{APCR}$ primers (Table 1). The preamplification PCR was performed in 25 $\mu \mathrm{L}$ multiplex reactions with Multiplex PCR Master Mix (Qiagen), $0.1 \mu \mathrm{mol}$ of each primer, and 2-9 $\mathrm{ng}$ cfDNA. The cycling program included $15 \mathrm{~min}$ at $95^{\circ} \mathrm{C}, 30$ cycles with $30 \mathrm{~s}$ at $94^{\circ} \mathrm{C}, 90 \mathrm{~s}$ at $63^{\circ} \mathrm{C}$, $90 \mathrm{~s}$ at $72^{\circ} \mathrm{C}$, followed by $10 \mathrm{~min}$ at $72^{\circ} \mathrm{C}$. Multiplex I included primers for RHD exons 3, 5 and 7, GAPDH and AMEL, multiplex II included primers for KEL, HPA-1, HPA-5 and AMEL, and multiplex III included primers for control SNP1, SNP2 and SNP3. After PCR, the products were purified with the QIAquick PCR Purification Kit (Qiagen) according to the manufacturer's instructions. The DNA concentration was measured by NanoDrop Lite (Thermo Fisher Scientific). 
Table 1. Primers for the preamplification PCR and TaqMan ${ }^{\mathrm{TM}}$ assays for $\mathrm{dPCR}$

\begin{tabular}{|c|c|c|}
\hline Target & $\begin{array}{l}\text { Primer sequence for preamplification }\left(5^{\prime}-3^{\prime}\right) \\
\text { and amplicon size }\end{array}$ & $\begin{array}{l}\text { Primer and probe sequence }\left(5^{\prime}-3^{\prime}\right) \\
\text { or commercial assay code (FAM or VIC } \\
\text { label as indicated) }\end{array}$ \\
\hline $\begin{array}{l}\text { RHD } \\
\text { exon } 3\end{array}$ & $\begin{array}{l}\text { for: TCTCAGTCGTCCTGGCTCTC } \\
\text { rev: TTACTGATGACCATCCTCAGGT } \\
\text { amplicon size: } 175 \text { bp }\end{array}$ & $\begin{array}{l}\text { for: GGCCACCATGAGTGCTTTG } \\
\text { rev: CTCCACCAGCACCATCACC } \\
\text { P: FAM-TGCTGATCTCAGTGGATG-MGB }\end{array}$ \\
\hline $\begin{array}{l}\text { RHD } \\
\text { exon } 5\end{array}$ & $\begin{array}{l}\text { for: TTCTGGCCAACCACCCTCTC } \\
\text { rev: GTCACCACGCTGACTGCTAC } \\
\text { amplicon size: } 148 \mathrm{bp}\end{array}$ & $\begin{array}{l}\text { for: CGCCCTCTTCTTGTGGATG } \\
\text { rev: GAACACGGCATTCTTCCTTTC } \\
\text { P: FAM-TCTGGCCAAGTTTCAAC-MGB }\end{array}$ \\
\hline $\begin{array}{l}\text { RHD } \\
\text { exon } 7\end{array}$ & $\begin{array}{l}\text { for: CAGCTCCATCATGGGCTACAA } \\
\text { rev: GGGTAAGCCCAGTGACCC } \\
\text { amplicon size: } 122 \mathrm{bp}\end{array}$ & $\begin{array}{l}\text { for: TGTGCTGCTGGTGCTTGA } \\
\text { rev: AGTGACCCACATGCCATTG } \\
\text { P: FAM-ACCGTCGGAGCCG-MGB }\end{array}$ \\
\hline GAPDH & $\begin{array}{l}\text { for: CCATCCСТTCTCCCCACAC } \\
\text { rev: GCTGTATTTTAACCCCCTAGTCC } \\
\text { amplicon size: } 123 \text { bp }\end{array}$ & $\begin{array}{l}\text { for: CCCCACACACATGCACTTACC } \\
\text { rev: CCTAGTCCCAGGGCTTTGATT } \\
\text { P: VIC-TAGGAAGGACAGGCAAC-MGB }\end{array}$ \\
\hline$A M E L$ & $\begin{array}{l}\text { for: CTGGGCACCCTGGTTATATC } \\
\text { rev: CTTGAGGCCAACCATCAGAG } \\
\text { amplicon size: } 201 \mathrm{bp}\end{array}$ & $\begin{array}{l}\text { for: CCCTGGGCTCTGTAAAGAATAGTG } \\
\text { rev: ATCAGAGCTTAAACTGGGAAGCTG } \\
\text { Px: VIC-TATCCCAGATGTTTCTC-MGB } \\
\text { Py: FAM-CCAAATAAAGTGGTTTCTC-MGB }\end{array}$ \\
\hline $\begin{array}{l}\text { KEL1/KEL2 } \\
(\mathrm{rs} 8176058)\end{array}$ & $\begin{array}{l}\text { for: GGCTCCACGGATCCTTATG } \\
\text { rev: TGTGTGGAGAGGCAGGATG } \\
\text { amplicon size: } 178 \text { bp }\end{array}$ & $\begin{array}{l}\text { C_1719_20 } \\
\text { KEL1: FAM; KEL2: VIC }\end{array}$ \\
\hline $\begin{array}{l}\mathrm{HPA}-1 \mathrm{a} / \mathrm{b} \\
(\mathrm{rs} 5918)\end{array}$ & $\begin{array}{l}\text { for: TGGACTTCTCTTTGGGCTCC } \\
\text { rev: TTGAGTGACCTGGGAGCTG } \\
\text { amplicon size: } 189 \mathrm{bp}\end{array}$ & $\begin{array}{l}\text { C_818008_30 } \\
\text { HPA-1a: FAM; HPA-1b: VIC }\end{array}$ \\
\hline $\begin{array}{l}\mathrm{HPA}-5 \mathrm{a} / \mathrm{b} \\
(\mathrm{rs} 1801106)\end{array}$ & $\begin{array}{l}\text { for: ACACCATTACAGACGTGCTC } \\
\text { rev: CTTTCCAAATGCAAGTTAAATTACC } \\
\text { amplicon size: } 165 \mathrm{bp}\end{array}$ & $\begin{array}{l}\text { C_27862812_10 } \\
\text { HPA-5a: FAM; HPA-5b: VIC }\end{array}$ \\
\hline $\begin{array}{l}\text { SNP1 } \\
(\mathrm{rs} 1357617)\end{array}$ & $\begin{array}{l}\text { for: CTCATTGGCAGCTGATGCAG } \\
\text { rev: GTCTCAAACGCCATCAGTATAG } \\
\text { amplicon size: } 169 \mathrm{bp}\end{array}$ & $\begin{array}{l}\text { C_11354314_10 } \\
\text { rs1357617-T: FAM; rs1357617-A: VIC }\end{array}$ \\
\hline $\begin{array}{l}\text { SNP2 } \\
(\mathrm{rs} 2830795)\end{array}$ & $\begin{array}{l}\text { for: GGCTGCAGGTTGATGATTTC } \\
\text { rev: TCTACCCAGATGCCTGAAATATG } \\
\text { amplicon size: } 189 \mathrm{bp}\end{array}$ & $\begin{array}{l}\text { C_3086569_20 } \\
\text { rs2830795-G: FAM; rs2830795-A: VIC }\end{array}$ \\
\hline $\begin{array}{l}\text { SNP3 } \\
(\mathrm{rs} 1028528)\end{array}$ & $\begin{array}{l}\text { for: AACAGATGTCCACAGCTGATG } \\
\text { rev: AGCAAGGGCATGGGGATCCA } \\
\text { amplicon size: } 177 \mathrm{bp}\end{array}$ & $\begin{array}{l}\text { C_2988456_20 } \\
\text { rs1028528-G: FAM; rs1028528-A: VIC }\end{array}$ \\
\hline
\end{tabular}

The concentration and the mean size of the preamplification products represented the basis for calculating the number of DNA molecules for dPCR by the following formula:

$$
\begin{aligned}
& \text { DNA molecules } / \mu L= \\
& \frac{(n g / \mu L \text { preamplification product }) \times \text { Avogadro constant }}{(\text { mean bp size of } P C R \text { products }) \times 660 \times 10^{9}}
\end{aligned}
$$

Avogadro constant $=6.022 \times 10^{23}$ molecules $/ \mathrm{mol} ; 660 \mathrm{~g} / \mathrm{mol}=\mathrm{av}$ erage mass of $1 \mathrm{bp}$ double-stranded DNA; $10^{9}=$ factor for $\mathrm{g}$ to $\mathrm{ng}$.

In order to elucidate the optimal number of DNA molecules, we performed pilot experiments $(n=3)$ in which we subjected $2 \times$ $10^{7}, 4 \times 10^{6}, 8 \times 10^{5}, 1.6 \times 10^{5}, 3.2 \times 10^{4}$, and $6.4 \times 10^{3}$ DNA mol- ecules per chip to dPCR analysis of RHD exon 7 in 5\% RHD mixed plasma samples.

\section{Assay Design and Chip-Based dPCR}

dPCR (QuantStudio ${ }^{\mathrm{TM}}$ 3D; Thermo Fisher Scientific) was performed on chips with 20,000 reaction wells, each with a 755-pL volume. We used self-designed ( $R H D, G A P D H$, and $A M E L)$ and commercial (KEL, HPA-1, HPA-5, and control SNPs) assays based on the TaqMan ${ }^{\mathrm{TM}}$ technology with two fluorescent dyes, FAM and VIC (Table 1). The assay design was based on previously published primer and probe sequences for RHD exons 3, 5 and 7, GAPDH, and $A M E L[14,18,19]$. The assays for RHD were designed with FAM-labeled probes specific for exon 3,5 , or 7 , and each included 


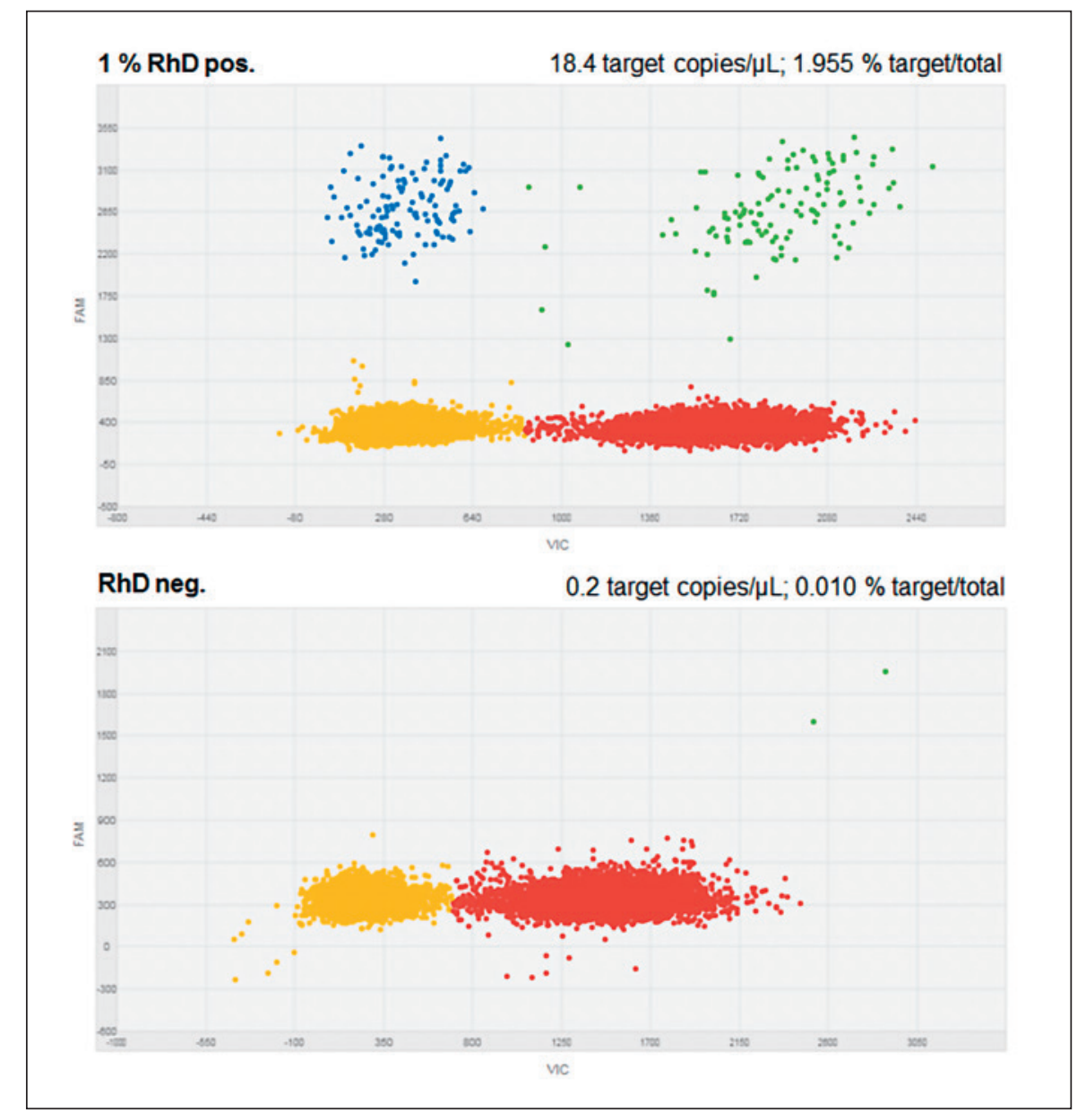

Fig. 1. Representative scatter plots of the RHD exon 7 digital PCR assay. Yellow dots: no amplification (ROX signal); red dots: positive reactions for GAPDH (VIC signal); blue dots: positive reactions for $R H D$ exon 7 (FAM signal); green dots: positive reactions for both targets (VIC + FAM signal). The Poisson-corrected values of target copies/ $\mu \mathrm{L}$ and $\%$ target/total are given. Upper panel: result from a plasma mixture with $1 \% \mathrm{D}$-positive plasma from an $R H D / d$ heterozygous donor, i.e., the proportion of the $R H D$ allele was $0.5 \%$. Lower panel: results from a D-negative plasma sample demonstrating the background of the assay.

GAPDH as a reference target detected by a VIC-labeled probe. The $A M E L$ assay contained a Y-specific probe (FAM channel) and an $\mathrm{X}$-specific probe (VIC channel) as an internal control. All other assays detected diallelic SNPs with one allele in the FAM channel (KEL1, HPA-1a, HPA-5b, SNP1a, SNP2a, and SNP3a) and one allele in the VIC channel (KEL2, HPA-1b, HPA-5a, SNP1b, SNP2b, and SNP3b). The KEL, HPA-1, and HPA-5 assays have been used before in a genotyping study [20].

The self-designed assays for $R H D$ exons 3,5 , and 7 were prepared as $40 \times$ concentrated mixtures containing $18 \mu \mathrm{mol}$ of each RHD primer, $3 \mu \mathrm{mol}$ of each GAPDH primer, and $5 \mu \mathrm{mol}$ of each probe. The $40 \times A M E L$ assay contained $18 \mu \mathrm{mol}$ of each $A M E L$ primer and $5 \mu \mathrm{mol}$ of each $A M E L$ probe. The commercial assays were purchased as $40 \times$ concentrates (Thermo Fisher Scientific). For each dPCR analysis, $4 \times 10^{6}$ preamplified DNA molecules in $7.1 \mu \mathrm{L}$ were mixed with $0.375 \mu \mathrm{L} 40 \times$ TaqMan $^{\mathrm{TM}}$ assay and $7.5 \mu \mathrm{L}$ dPCR Master Mix V2 containing ROX as a reference dye (Thermo Fisher Scientific). The reaction mixture was loaded onto a chip and covered with oil using the QuantStudio ${ }^{\mathrm{TM}}$ 3D Chip Loader device (Thermo Fisher Scientific). The cycling program for dPCR of RHD exon 7, AMEL, KEL, SNP1, SNP2, and SNP3 consisted of $10 \mathrm{~min}$ at $96^{\circ} \mathrm{C}$ followed by 40 cycles with $30 \mathrm{~s}$ at $98^{\circ} \mathrm{C}$ and $2 \mathrm{~min}$ at $56^{\circ} \mathrm{C}$. For RHD exon 3, RHD exon 5, HPA-1, and HPA-5, the annealing temperature was $52^{\circ} \mathrm{C}$.

Analysis of dPCR Results

After cycling, the dPCR chips were scanned for the FAM and VIC signals (QuantStudio ${ }^{\mathrm{TM}}$ 3D Chip Reader; Thermo Fisher
Scientific) and the data were uploaded into the QuantStudio ${ }^{\mathrm{TM}}$ 3D AnalysisSuite cloud software (https://apps.thermofisher. com/quantstudio3d). Based on the fluorescence signals and statistical correction using Poisson distribution, the software allowed the calculation of target copies per microliter and target/ total (\%) values. In addition, the uncorrected raw data were displayed in scatter plots (Fig. 1). Poisson correction is necessary to consider reaction wells containing more than one target molecule [21].

The QuantStudio ${ }^{\text {TM }}$ 3D AnalysisSuite cloud software provided the final results; however, to give a deeper understanding of how the values are calculated, the procedure is briefly explained. First, the numbers of filled wells (ROX positive) and wells negative for FAM or VIC were determined and used to calculate $\mathrm{P}_{0}$ for the FAM channel and the VIC channel:

$$
P_{0}=\frac{\text { Number of FAM- or VIC-negative wells }}{\text { Number of filled wells }} .
$$

Second, the correction factor $\lambda$ was introduced to consider the probability of more than one target molecule in a filled well: $\lambda=$ $-\ln P_{0}$.

Third, the concentration $c($ copies $/ \mu \mathrm{L})$ was calculated:

$$
c=\frac{\lambda}{V}
$$

the reaction volume $(V)$ of a single well on the chip is $755 \mathrm{pL}=$ $7.55 \times 10^{-4} \mu \mathrm{L}$. 
Table 2. Results from digital PCR analysis of RHD exon 7 in a dilution series of preamplified cell-free DNA from 5\% mixed plasma samples

\begin{tabular}{lcc}
\hline $\begin{array}{l}\text { Preamplified } \\
\text { molecules/chip }\end{array}$ & Target copies/ $\mu \mathrm{L}^{\mathrm{a}}$ & Target/total $^{\mathrm{a}}, \%$ \\
\hline $2 \times 10^{7}$ & $295.5 \pm 208.3$ & $5.14 \pm 2.13$ \\
$4 \times 10^{6}$ & $10.6 \pm 7.8$ & $4.86 \pm 0.87$ \\
$8 \times 10^{5}$ & $4.5 \pm 3.5$ & $5.82 \pm 1.79$ \\
$1.6 \times 10^{5}$ & $2.1 \pm 1.2$ & $4.44 \pm 0.90$ \\
$3.2 \times 10^{4}$ & $0.5 \pm 0.2$ & $10.51 \pm 4.29$ \\
$6.4 \times 10^{3}$ & $0.4 \pm 0.0$ & $30.65 \pm 4.40$ \\
\hline
\end{tabular}

${ }^{\mathrm{a}}$ Mean \pm SD values from biological triplicates.

Table 3. Results of the RHD, KEL, and HPA digital PCR assays from the mixed plasma samples

\begin{tabular}{|c|c|c|c|}
\hline Target & $\begin{array}{l}\% \text { heterozygous } \\
\text { plasma } \\
\text { (\% target allele) }\end{array}$ & $\begin{array}{l}\text { Target } \\
\text { copies } / \mu \mathrm{L}^{\mathrm{a}}\end{array}$ & $\begin{array}{l}\text { Target/total }{ }^{\mathrm{a}} \text {, } \\
\%\end{array}$ \\
\hline RHD exon 3 & $\begin{array}{l}5.0(2.5) \\
1.0(0.5) \\
0.5(0.25) \\
0.1(0.05) \\
0.0(0)\end{array}$ & $\begin{array}{c}33.6 \pm 13.6 \\
4.1 \pm 0.9 \\
5.2 \pm 2.9 \\
1.5 \pm 0.4 \\
4.9 \pm 3.1\end{array}$ & $\begin{array}{l}3.54 \pm 0.36 \\
1.00 \pm 0.44 \\
0.49 \pm 0.12 \\
0.38 \pm 0.19 \\
0.60 \pm 0.20\end{array}$ \\
\hline$R H D$ exon 5 & $\begin{array}{l}5.0(2.5) \\
1.0(0.5) \\
0.5(0.25) \\
0.1(0.05) \\
0.0(0)\end{array}$ & $\begin{array}{r}18.0 \pm 4.9 \\
6.3 \pm 4.4 \\
2.0 \pm 1.1 \\
2.3 \pm 3.1 \\
0.0 \pm 0.0\end{array}$ & $\begin{array}{l}6.47 \pm 2.04 \\
2.06 \pm 0.72 \\
0.85 \pm 0.77 \\
0.28 \pm 0.33 \\
0.00 \pm 0.01\end{array}$ \\
\hline RHD exon 7 & $\begin{array}{l}5.0(2.5) \\
1.0(0.5) \\
0.5(0.25) \\
0.1(0.05) \\
0.0(0)\end{array}$ & $\begin{array}{c}82.6 \pm 44.8 \\
36.9 \pm 25.3 \\
2.5 \pm 3.2 \\
0.7 \pm 0.3 \\
0.6 \pm 0.7\end{array}$ & $\begin{array}{l}4.36 \pm 0.88 \\
2.20 \pm 0.45 \\
0.48 \pm 0.65 \\
0.08 \pm 0.03 \\
0.04 \pm 0.05\end{array}$ \\
\hline KEL1 & $\begin{array}{l}5.0(2.5) \\
1.0(0.5) \\
0.5(0.25) \\
0.1(0.05) \\
0.0(0)\end{array}$ & $\begin{array}{r}33.5 \pm 1.5 \\
8.8 \pm 5.3 \\
5.4 \pm 5.0 \\
1.6 \pm 0.4 \\
1.6 \pm 0.5\end{array}$ & $\begin{array}{l}2.33 \pm 0.27 \\
0.64 \pm 0.47 \\
0.40 \pm 0.40 \\
0.08 \pm 0.01 \\
0.07 \pm 0.02\end{array}$ \\
\hline HPA-1a & $\begin{array}{l}5.0(2.5) \\
1.0(0.5) \\
0.5(0.25) \\
0.1(0.05) \\
0.0(0)\end{array}$ & $\begin{array}{c}83.5 \pm 36.0 \\
22.1 \pm 21.2 \\
8.0 \pm 4.8 \\
1.4 \pm 0.1 \\
0.1 \pm 0.0\end{array}$ & $\begin{array}{l}2.32 \pm 1.01 \\
0.63 \pm 0.73 \\
0.71 \pm 0.37 \\
0.12 \pm 0.03 \\
0.01 \pm 0.01\end{array}$ \\
\hline HPA-1b & $\begin{array}{l}5.0(2.5) \\
1.0(0.5) \\
0.5(0.25) \\
0.1(0.05) \\
0.0(0)\end{array}$ & $\begin{array}{r}46.1 \pm 4.2 \\
17.0 \pm 5.9 \\
9.5 \pm 4.5 \\
6.7 \pm 2.5 \\
4.4 \pm 0.2\end{array}$ & $\begin{array}{l}2.41 \pm 0.36 \\
0.76 \pm 0.31 \\
0.58 \pm 0.25 \\
0.31 \pm 0.03 \\
0.28 \pm 0.11\end{array}$ \\
\hline HPA-5b & $\begin{array}{l}5.0(2.5) \\
1.0(0.5) \\
0.5(0.25) \\
0.1(0.05) \\
0.0(0)\end{array}$ & $\begin{array}{c}25.8 \pm 4.7 \\
20.3 \pm 23.1 \\
1.8 \pm 1.1 \\
2.6 \pm 1.6 \\
2.1 \pm 1.4\end{array}$ & $\begin{array}{l}1.91 \pm 0.47 \\
0.55 \pm 0.28 \\
0.08 \pm 0.00 \\
0.13 \pm 0.06 \\
0.07 \pm 0.01\end{array}$ \\
\hline
\end{tabular}

${ }^{\mathrm{a}}$ Mean $\pm \mathrm{SD}$ values from biological triplicates.
These calculations were carried out for both channels FAM and VIC. With the concentration of molecules ( $c F A M$ and $c V I C)$, the target/total ratio was calculated

- for target detection in the FAM channel:

$$
\text { target/total }(\%)=\frac{c F A M}{c F A M+c V I C} \times 100 ;
$$

- for target detection in the VIC channel:

$$
\text { target/total }(\%)=\frac{c V I C}{c F A M+c V I C} \times 100 .
$$

\section{Results}

\section{Preamplification of the Target Loci}

The standard protocol for APCR is designed for the analysis of nanograms of genomic DNA; however, the amount of cfDNA in plasma samples is much lower. In preliminary experiments, we used cfDNA directly in dPCR for genotyping RHD or SNPs, and, as expected, the number of evaluable signals was rather low $(<1,000$; not shown). In order to increase the number of evaluable signals, we introduced preamplification of the target loci. The optimal number of preamplified target molecules for dPCR was established in mixed plasma samples containing 5\% heterozygous D-positive plasma and 95\% D-negative plasma.

cfDNA was extracted from the plasma mixtures and conducted to preamplification PCR with multiplex I, containing primers for $R H D, G A P D H$, and $A M E L$. After purification, dilution series from $2 \times 10^{7}$ to $6.4 \times 10^{3} \mathrm{~mol}$ ecules per chip of the preamplification products were analyzed by dPCR for RHD exon 7 (Table 2). The analysis of $2 \times 10^{7}, 4 \times 10^{6}, 8 \times 10^{5}$, and $1.6 \times 10^{5}$ molecules revealed similar results of approximately $5 \%$ target/total; however, an overload of the chips was observed for $2 \times$ $10^{7}$ molecules. Lower numbers of molecules $\left(3.2 \times 10^{4}\right.$ and $6.4 \times 10^{3}$ ) lead to overestimation of the target/total ratio. The results obtained from $4 \times 10^{6}$ molecules were the most robust; thus, $4 \times 10^{6}$ preamplified molecules were used in all dPCR experiments described below.

\section{Validation of the dPCR Assays}

Plasma samples from volunteer donors with known genotypes for the investigated targets were used to validate the dPCR assays with regard to sensitivity and specificity. In order to simulate a fetal DNA fraction in the plasma of pregnant women, we mixed plasma of donors negative for the target allele with plasma of heterozygous donors in biological triplicates, i.e., 3 different donors each. All tests were performed on plasma mixtures containing $5 \%, 1 \%, 0.5 \%$, and $0.1 \%$ heterozygous plasma. In addition, the background of the assays was tested in plasma samples of donors negative for the target. For testing $R H D$, specific assays for the detection of exons 3,5 , and 7 
Fig. 2. Representative scatter plots of the HPA-1 digital PCR assay. Yellow dots: no amplification (ROX signal); red dots: positive reactions for the HPA-1b allele (VIC signal); blue dots: positive reactions for the HPA-1a allele (FAM signal); green dots: positive reactions for both alleles (VIC + FAM signal). The Poisson-corrected values of target copies $/ \mu \mathrm{L}$ and $\%$ target/total are given. Upper panel: result from a plasma mixture with $1 \%$ HPA-1ab heterozygous plasma, i.e., the proportion of the HPA-1a allele was $0.5 \%$. Lower panel: results from an HPA-1bb plasma sample demonstrating the background of the assay.

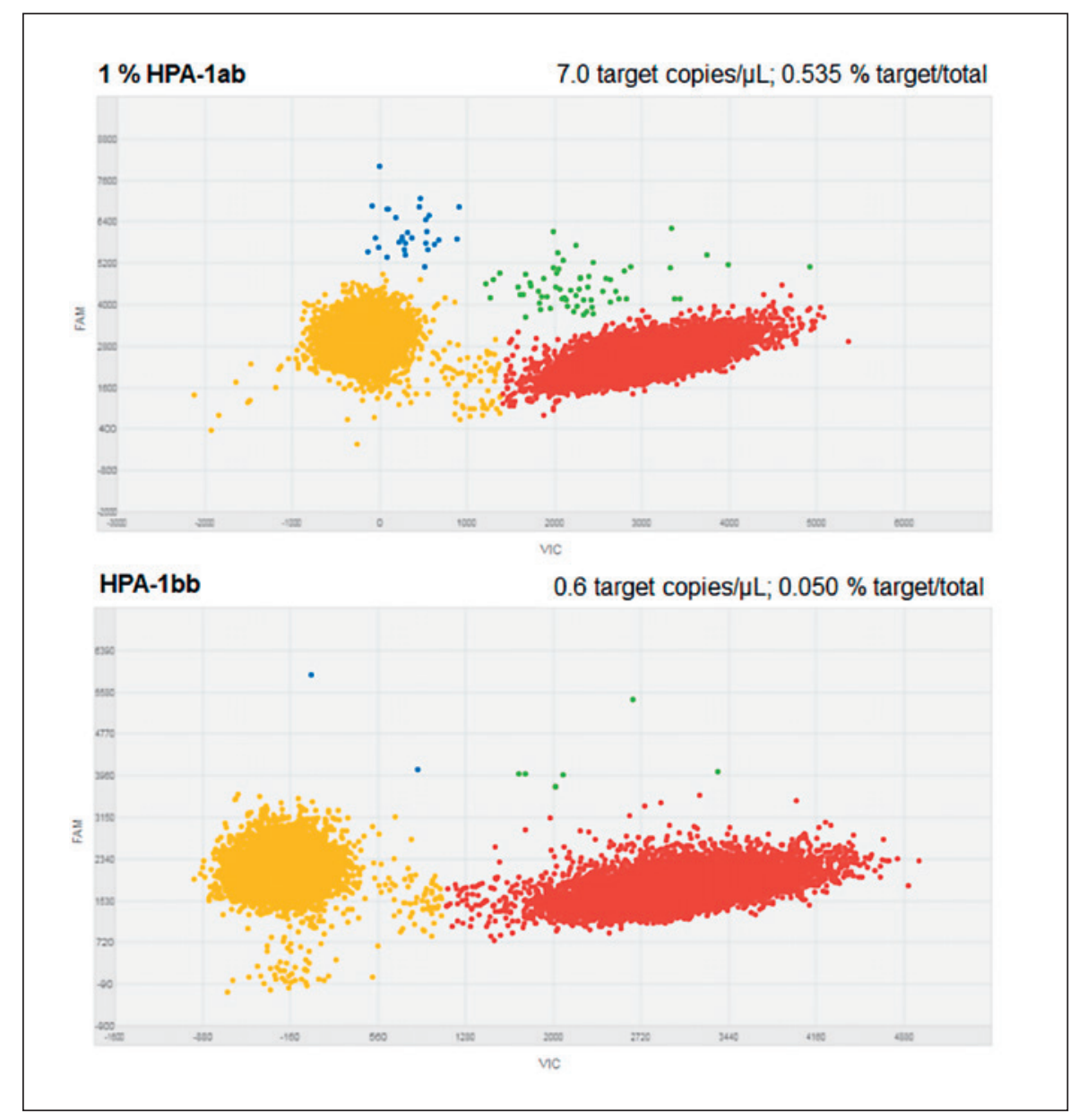

were established. GAPDH was used as a reference target in all $R H D$ assays to allow target/total calculation. $R H D$ exons 5 and 7 were detected reliably in $5 \%, 1 \%$, and $0.5 \%$ of the mixed plasma samples containing $2.5 \%, 0.5 \%$, and $0.25 \%$ of the target, respectively (Table 3 ; Fig. 1 ). The background of the exon 5 and 7 assays in D-negative plasma revealed $0.00 \pm 0.01 \%$ and $0.04 \pm 0.05 \%$ target/total, respectively. The higher background for the exon 3 assay $(0.60 \pm 0.20 \%$ target/total $)$, prevented specific RHD detection in the $1.0 \%, 0.5 \%$, and $0.1 \%$ plasma mixes (Table $3)$. Technical triplicates of dPCR from a $5 \%$ mixed plasma sample indicated a coefficient of variation of $14 \%$ and $5 \%$ for the RHD exon 5 and exon 7 assays, respectively.

The Kell (KEL1) blood group antigen is encoded by the variant allele (T) of the diallelic SNP c.578C $>\mathrm{T}$ in the KEL gene. The validation of the assay for detection of the KEL1 allele revealed a background of $0.07 \pm 0.02 \%$ and a high sensitivity to detect the target in $1 \%$ and $5 \%$ mixed plasma samples (Table 3). With regard to FNAIT, the HPA-1a antigen is the clinically most relevant one and is encoded by the wild-type allele (T) of the diallelic SNP c.176T $>$ C in the ITGB3 gene. The high sensitivity and specificity of the HPA-1 assay allowed a reliable detection of the HPA- 1a allele even in the $0.1 \%$ mixed plasma samples $(0.05 \%$ target) with $0.12 \pm 0.03 \%$ target/total (Table 3; Fig. 2). The background was very low at $0.01 \pm 0.01 \%$ target/total. The HPA- 1 assay was also validated for detection of the HPA$1 \mathrm{~b}$ allele, which revealed a significantly higher background of $0.28 \pm 0.11 \%$ target/total. Therefore, the detection limit for the HPA-1b allele was higher than for the HPA-1a allele and required at least $0.5 \%$ mixed plasma (Table 3). For the HPA-5 assay, we found a lower sensitivity and a higher background than for the HPA-1 assay. Reliable detection of the clinically relevant HPA-5b allele could be achieved in $5 \%$ and $1 \%$ mixed plasma. The background values and the values for the $0.1 \%$ and $0.5 \%$ mixed plasma were very similar (Table 3 ).

The gonosomal locus AMEL contains a dimorphism with a 6-bp insertion on the Y chromosome compared to the $\mathrm{X}$ chromosome [16]. We established a dPCR assay for $A M E L$ as a control marker for male fetus detection. The Y-chromosomal allele could be detected reliably in 5\% and $1 \%$ mixed plasma. The background was $0.14 \pm 0.05 \%$ target/total and overlapped with the values for $0.5 \%$ and $0.1 \%$ mixed plasma (Table 4 ). In order to introduce additional control markers for the detection of fetal DNA, 
we selected diallelic SNPs from the SNPforID panel [17]. In this proof of principle, we tested three SNP markers for both alleles and used $1 \%$ plasma mixtures and also determined the background for the assays. All assays allowed reliable detection of the target alleles in the $1 \%$ plasma mixtures and showed a low background in the target-negative plasma (Table 4).

\section{Analysis of Maternal Plasma}

In a pilot study, the dPCR methods for the targets (RHD exons 5 and 7, KEL1, HPA-1a, and HPA-5b) and the control markers (AMEL-Y and SNP1-3) were applied to plasma samples from 13 selected cases of pregnancy at different gestational ages (Table 5). In 10 cases, the mothers were $\mathrm{D}$ negative, and the cfDNA analysis for RHD exons 5 and 7 indicated a D-positive fetus in 9 cases. Case No. 6 was negative for both RHD exons. The KEL1 allele was analyzed in 12 cases, and all were negative. The HPA1a allele could be analyzed in 3 HPA- 1 bb mothers, and 1 case (No. 2) showed a positive result in plasma cfDNA. Nine of the mothers were HPA-5aa, and the HPA-5b allele was detectable in case No. 3. The Y-chromosomal marker AMEL-Y was analyzed in all samples and indicated a male fetus in 3 cases, including the RhD-negative case No. 6. In case No. 4, a positive control for cffDNA was missing because all of the analyzed targets (KEL1, HPA-1a, and HPA-5b) and control markers (AMEL-Y and SNP1-3) were negative. Further markers need to be analyzed in this case to prove the presence of reasonable amounts of fetal DNA in the maternal plasma. A DNA sample of the newborn was available in 3 of the 13 cases, and the proposed fetal genotypes from NIPT could be confirmed.

\section{Discussion}

We presented the validation of NIPT assays for blood cell antigens using plasma cfDNA and chip-based dPCR. Preamplification of the target loci was introduced in order to increase the sensitivity of the assays as a prerequisite for the detection of fetal alleles at an early stage of pregnancy. Further improvement of sensitivity may be achieved when using specialized blood collection tubes (Cell-Free DNA BCT ${ }^{\circledR}$ CE; Streck Inc., La Vista, NE, USA) instead of EDTA tubes to prevent genomic DNA release from nucleated blood cells. It has to be shown whether the sensitivity of dPCR assays with cfDNA from Streck tubes without preamplification is comparable to our protocol with EDTA tubes and preamplification of the targets. Even without preamplification, a higher sensitivity of dPCR compared to qPCR for RHD exon 5 and 7 detection in samples with $<2 \%$ cffDNA was demonstrated [22]. However, we suppose that preamplification
Table 4. Results of the control assays from the mixed plasma samples

\begin{tabular}{|c|c|c|c|}
\hline Target & $\begin{array}{l}\% \text { heterozygous } \\
\text { plasma } \\
\text { (\% target allele) }\end{array}$ & $\begin{array}{l}\text { Target } \\
\text { copies } / \mu \mathrm{L}^{\mathrm{a}}\end{array}$ & $\begin{array}{l}\text { Target/total }{ }^{\mathrm{a}} \text {, } \\
\%\end{array}$ \\
\hline AMEL-Y & $\begin{array}{l}5.0(2.5) \\
1.0(0.5) \\
0.5(0.25) \\
0.1(0.05) \\
0.0(0)\end{array}$ & $\begin{array}{l}6.4 \pm 2.2 \\
4.8 \pm 6.2 \\
0.4 \pm 0.2 \\
0.2 \pm 0.1 \\
0.2 \pm 0.1\end{array}$ & $\begin{array}{l}4.20 \pm 1.70 \\
1.34 \pm 1.01 \\
0.23 \pm 0.18 \\
0.23 \pm 0.20 \\
0.14 \pm 0.05\end{array}$ \\
\hline $\begin{array}{l}\text { SNP1a } \\
\text { (rs1357617A) }\end{array}$ & $\begin{array}{l}1.0(0.5) \\
0.0(0)\end{array}$ & $\begin{array}{l}3.5 \pm 1.2 \\
0.5 \pm 0.4\end{array}$ & $\begin{array}{l}0.52 \pm 0.16 \\
0.01 \pm 0.01\end{array}$ \\
\hline $\begin{array}{l}\text { SNP1b } \\
(\text { rs1357617T) }\end{array}$ & $\begin{array}{l}1.0(0.5) \\
0.0(0)\end{array}$ & $\begin{array}{r}16.2 \pm 9.2 \\
0.0 \pm 0.0\end{array}$ & $\begin{array}{l}1.96 \pm 0.73 \\
0.00 \pm 0.00\end{array}$ \\
\hline $\begin{array}{l}\text { SNP2a } \\
(\mathrm{rs} 2830795 \mathrm{G})\end{array}$ & $\begin{array}{l}1.0(0.5) \\
0.0(0)\end{array}$ & $\begin{array}{r}27.0 \pm 7.7 \\
0.4 \pm 0.3\end{array}$ & $\begin{array}{l}3.24 \pm 0.38 \\
0.01 \pm 0.00\end{array}$ \\
\hline $\begin{array}{l}\text { SNP2b } \\
(\mathrm{rs} 2830795 \mathrm{~A})\end{array}$ & $\begin{array}{l}1.0(0.5) \\
0.0(0)\end{array}$ & $\begin{array}{l}8.9 \pm 4.3 \\
0.1 \pm 0.0\end{array}$ & $\begin{array}{l}1.52 \pm 0.80 \\
0.00 \pm 0.00\end{array}$ \\
\hline $\begin{array}{l}\text { SNP3a } \\
\text { (rs1028528G) }\end{array}$ & $\begin{array}{l}1.0(0.5) \\
0.0(0)\end{array}$ & $\begin{array}{l}6.0 \pm 5.3 \\
0.5 \pm 0.1\end{array}$ & $\begin{array}{l}0.24 \pm 0.01 \\
0.01 \pm 0.01\end{array}$ \\
\hline $\begin{array}{l}\text { SNP3b } \\
\text { (rs1028528A) }\end{array}$ & $\begin{array}{l}1.0(0.5) \\
0.0(0)\end{array}$ & $\begin{array}{c}18.1 \pm 11.6 \\
1.0 \pm 0.5\end{array}$ & $\begin{array}{l}0.56 \pm 0.07 \\
0.03 \pm 0.01\end{array}$ \\
\hline
\end{tabular}

${ }^{\text {a }}$ Mean \pm SD values from biological triplicates.

is advantageous to the sensitive detection of fetal SNP alleles.

Our technical validation supported the use of dPCR for NIPT in early stages of pregnancy. Detection of $R H D$ exons 5 and 7 in an $\mathrm{RhD}$-negative background was feasible in plasma mixtures containing only $0.25 \% R H D$ allele. In 3 cases of RhD-negative mothers, RHD exon 7 could be detected at an early stage (gestational weeks 9 and 12). However, the detection of SNP alleles such as KEL1, HPA-1a, HPA-5b, and others is more challenging regarding sensitivity and specificity. Our NIPT assays allowed SNP allele detection in plasma mixtures containing at least $0.5 \%$ of the targeted allele. In the validation study, the HPA-1a assay was the most sensitive and allowed the detection of even a $0.05 \%$ target. A similar sensitivity was reported for rare SNP allele detection using digital droplet PCR [15]. In 1 case of an HPA-1bb mother, we were able to detect the fetal HPA-1a allele at gestational week 13 .

Our dPCR assays allow the detection of rare molecules in cfDNA and are, therefore, suitable for NIPT. For the detection of fetal RHD, HPA, and other blood group alleles using a massive parallel sequencing method, a $2 \%$ target/total cutoff was defined for reliable detection of a target allele [12]. We found that the background (falsepositive signals) in APCR is significantly lower and the target/total cutoff can in general be defined as $0.5 \%$. In 
Table 5. Results given in target copies/ $\mu \mathrm{L}$ (\% targets/total) from digital PCR analysis of cell-free DNA from pregnant women

\begin{tabular}{|c|c|c|c|c|c|c|c|c|c|c|c|}
\hline $\begin{array}{l}\text { Case } \\
\text { No. }\end{array}$ & $\begin{array}{l}\text { GA, } \\
\text { week }\end{array}$ & $\begin{array}{l}\text { RHD } \\
\text { exon } 5\end{array}$ & $\begin{array}{l}\text { RHD } \\
\text { exon } 7\end{array}$ & KEL1 & HPA-1a & HPA-5b & AMEL-Y & SNP1 & SNP2 & SNP3 & $\begin{array}{l}\text { Proposed fetal } \\
\text { genotypes }\end{array}$ \\
\hline 1 & 25 & $\begin{array}{l}20.1 \\
(0.37)\end{array}$ & $\begin{array}{l}56.3 \\
(0.96)\end{array}$ & $\begin{array}{l}0.3 \\
(0.01)\end{array}$ & $\begin{array}{l}0.9 \\
(0.01)\end{array}$ & $\begin{array}{l}0.3 \\
(0.01)\end{array}$ & $\begin{array}{l}0.4 \\
(0.02)\end{array}$ & nt & $\mathrm{nt}$ & $\begin{array}{l}\text { b: } 10.6 \\
(0.25)\end{array}$ & $\begin{array}{l}\text { Dd; KEL2; HPA-1bb; } \\
\text { HPA-5aa; XX; SNP3ab }\end{array}$ \\
\hline 2 & 13 & $\mathrm{nt}$ & $\mathrm{nt}$ & $\begin{array}{l}0.1 \\
(0.00)\end{array}$ & $\begin{array}{l}8.0 \\
(0.18)\end{array}$ & $\begin{array}{l}0.3 \\
(0.01)\end{array}$ & $\begin{array}{l}0.8 \\
(0.01)\end{array}$ & $\mathrm{nt}$ & $\mathrm{nt}$ & nt & $\begin{array}{l}\text { KEL2; HPA-1ab; } \\
\text { HPA-5aa; XX }\end{array}$ \\
\hline 3 & 26 & nt & nt & $\begin{array}{l}0.0 \\
(0.00)\end{array}$ & nt & $\begin{array}{l}2.6 \\
(0.23)\end{array}$ & $\begin{array}{l}3.1 \\
(0.06)\end{array}$ & $\begin{array}{l}\mathrm{b}: 2.1 \\
(0.05)\end{array}$ & $\mathrm{nt}$ & nt & $\begin{array}{l}\text { KEL2; HPA-5ab; XX; } \\
\text { SNP1aa }\end{array}$ \\
\hline 4 & 9 & $\mathrm{nt}$ & $\mathrm{nt}$ & $\begin{array}{l}0.1 \\
(0.00)\end{array}$ & $\begin{array}{l}1.6 \\
(0.02)\end{array}$ & $\begin{array}{l}1.2 \\
(0.02)\end{array}$ & $\begin{array}{l}0.7 \\
(0.01)\end{array}$ & $\begin{array}{l}\text { a: } 1.8 \\
(0.02)\end{array}$ & $\begin{array}{l}\text { b: } 1.0 \\
(0.04)\end{array}$ & $\begin{array}{l}\text { a: } 0.1 \\
(0.00)\end{array}$ & $\begin{array}{l}\text { KEL2; HPA-1bb; } \\
\text { HPA-5aa; XX; } \\
\text { SNP1bb; SNP2aa; } \\
\text { SNP3bb }\end{array}$ \\
\hline 5 & 39 & $\begin{array}{l}1,104.3 \\
(14.00)\end{array}$ & $\begin{array}{l}989.2 \\
(33.97)\end{array}$ & $\begin{array}{l}0.2 \\
(0.00)\end{array}$ & $\mathrm{nt}$ & $\mathrm{nt}$ & $\begin{array}{l}0.5 \\
(0.01)\end{array}$ & $\mathrm{nt}$ & $\begin{array}{l}\text { b: } 1.4 \\
(0.03)\end{array}$ & $\mathrm{nt}$ & $\begin{array}{l}\text { Dd; KEL2; XX; } \\
\text { SNP2aa }\end{array}$ \\
\hline 6 & 34 & $\begin{array}{l}0.9 \\
(0.10)\end{array}$ & $\begin{array}{l}0.4 \\
(0.01)\end{array}$ & $\begin{array}{l}0.1 \\
(0.00)\end{array}$ & $\mathrm{nt}$ & $\begin{array}{l}0.6 \\
(0.01)\end{array}$ & $\begin{array}{l}46.9 \\
(0.82)\end{array}$ & nt & $\begin{array}{l}\text { b: } 1.9 \\
(0.04)\end{array}$ & $\mathrm{nt}$ & $\begin{array}{l}\text { dd; KEL2; HPA-5aa; } \\
\text { XY; SNP2aa }\end{array}$ \\
\hline 7 & 36 & $\begin{array}{l}221.8 \\
(3.04)\end{array}$ & $\begin{array}{l}709.2 \\
(7.14)\end{array}$ & $\begin{array}{l}0.2 \\
(0.00)\end{array}$ & nt & $\mathrm{nt}$ & $\begin{array}{l}8.0 \\
(0.15)\end{array}$ & $\mathrm{nt}$ & $\begin{array}{l}\text { b: } 0.8 \\
(0.03)\end{array}$ & $\begin{array}{l}\text { b: } 0.5 \\
(0.01)\end{array}$ & $\begin{array}{l}\text { Dd; KEL2; XY; } \\
\text { SNP2aa; SNP3aa }\end{array}$ \\
\hline 8 & 33 & $\begin{array}{l}20.2 \\
(0.43)\end{array}$ & $\begin{array}{l}408.8 \\
(3.82)\end{array}$ & $\begin{array}{l}0.1 \\
(0.00)\end{array}$ & nt & $\begin{array}{l}1.5 \\
(0.03)\end{array}$ & $\begin{array}{l}0.4 \\
(0.01)\end{array}$ & $\begin{array}{l}\text { a: } 2.2 \\
(0.08)\end{array}$ & $\mathrm{nt}$ & $\mathrm{nt}$ & $\begin{array}{l}\text { Dd; KEL2; HPA-5aa; } \\
\text { XX; SNP1bb }\end{array}$ \\
\hline 9 & 12 & $\mathrm{nt}$ & $\begin{array}{l}269.9 \\
(12.30)\end{array}$ & $\mathrm{nt}$ & nt & $\begin{array}{l}2.1 \\
(0.06)\end{array}$ & $\begin{array}{l}0.2 \\
(0.13)\end{array}$ & $\begin{array}{l}\text { b: } 81.5 \\
(12.94)\end{array}$ & $\begin{array}{l}\text { b: } 20.0 \\
(3.01)\end{array}$ & $\mathrm{nt}$ & $\begin{array}{l}\text { Dd; KEL2; HPA-5aa; } \\
\text { XX; SNP1ab; SNP2ab }\end{array}$ \\
\hline 10 & 9 & $\begin{array}{l}16.1 \\
(0.44)\end{array}$ & $\begin{array}{l}18.0 \\
(0.56)\end{array}$ & $\begin{array}{l}1.3 \\
(0.04)\end{array}$ & $\mathrm{nt}$ & $\mathrm{nt}$ & $\begin{array}{l}0.8 \\
(0.05)\end{array}$ & $\mathrm{nt}$ & $\begin{array}{l}\text { b: } 6.8 \\
(0.31)\end{array}$ & $\begin{array}{l}\text { b: } 7.8 \\
(0.27)\end{array}$ & $\begin{array}{l}\text { Dd; KEL2; XX; } \\
\text { SNP2ab; SNP3ab }\end{array}$ \\
\hline 11 & 9 & $\begin{array}{l}40.4 \\
(1.24)\end{array}$ & $\begin{array}{l}79.8 \\
(3.51)\end{array}$ & $\begin{array}{l}0.0 \\
(0.00)\end{array}$ & $\mathrm{nt}$ & $\begin{array}{l}0.5 \\
(0.10)\end{array}$ & $\begin{array}{l}9.4 \\
(1.23)\end{array}$ & $\begin{array}{l}\text { a: } 2.8 \\
(0.10)\end{array}$ & $\begin{array}{l}\text { b: } 10.8 \\
(0.45)\end{array}$ & $\mathrm{nt}$ & $\begin{array}{l}\text { Dd; KEL2; HPA-5aa; } \\
\text { XY; SNP1bb; SNP2ab }\end{array}$ \\
\hline 12 & 24 & $\begin{array}{l}54.2 \\
(1.71)\end{array}$ & $\begin{array}{l}196.4 \\
(4.99)\end{array}$ & $\begin{array}{l}0.1 \\
(0.00)\end{array}$ & nt & $\begin{array}{l}1.7 \\
(0.02)\end{array}$ & $\begin{array}{l}0.2 \\
(0.01)\end{array}$ & $\begin{array}{l}\text { b: } 0.3 \\
(0.01)\end{array}$ & $\mathrm{nt}$ & $\mathrm{nt}$ & $\begin{array}{l}\text { Dd; KEL2; HPA-5aa; } \\
\text { SNP1aa }\end{array}$ \\
\hline 13 & 21 & nt & $\begin{array}{l}129.5 \\
(5.82)\end{array}$ & $\begin{array}{l}0.0 \\
(0.00)\end{array}$ & nt & nt & $\begin{array}{l}0.6 \\
(0.16)\end{array}$ & nt & nt & nt & Dd; KEL2; XX \\
\hline
\end{tabular}

The targeted SNP allele (a or b) is indicated; positive results are highlighted (gray shading); a DNA sample of the newborn was available in cases No. 3, 5, and 11. GA, gestational age; nt, not tested because maternal genomic DNA was positive, or the SNP was heterozygous.

our hands, chip-based dPCR is a robust method; during validation, dPCR had failed and had to be repeated in only about $1 \%$ of the tests.

The combination of antenatal and postnatal administration of anti-D immune prophylaxis is a current standard to prevent HDFN in D-negative women [23]. Since the availability of anti-D immunoglobulin is limited, targeted use for antenatal prophylaxis is a reasonable contribution to health economics $[24,25]$. The immune destruction of blood cells (in HDFN or FNAIT) mediated by other antigens can be prevented by antenatal administration of high-dose intravenous immunoglobulin [26]. Antigen-specific immune prophylaxis (anti-KEL1 or others) should have fewer side effects, but it is not available.
To prevent immune destruction of platelets in FNAIT, the EU-funded PROFNAIT consortium is developing an immune prophylaxis against HPA-1a-mediated FNAIT (www.profnait.eu).

Prenatal determination of the fetal antigen status is a prerequisite for establishing targeted immune prophylaxis. In countries with nationwide $\mathrm{RhD}$-NIPT, gestational week $25-27$ is the common time point for the screening of $\mathrm{D}$-negative women. In most protocols, $R H D$ exons 5 and 7 are detected by qPCR methods. Our APCR protocol is based on the same TaqMan assays $[14,18]$ and includes preamplification of the target loci. However, preamplification is supposedly not needed for $R H D$ detection at later gestational ages. In the pilot study, RHD exon 7 detec- 
tion revealed high numbers of target copies per microliter in samples from the second or third trimester of pregnancy. In these cases, dPCR is probably not advantageous with regard to sensitivity and specificity when compared to qPCR. The availability of an internal control is a benefit of dPCR, whereas the costs per target (approx. EUR 10) are significantly higher than for qPCR.

RHD genotyping is hampered by the highly homologous RHCE gene. Rearrangement of the two genes lead to RHD-RHCE hybrid genes with exons from one gene replaced by the corresponding exons of the other gene. This is a common molecular basis of partial $\mathrm{RhD}$ phenotypes and has to be considered in RHD-specific exon amplification by PCR methods [27, 28]. The most common partial $\mathrm{D}$ phenotype is category DVI, which is caused by replacement of RHD exon 5 and others. Our and other NIPT for the detection of $R H D$ exon 5 would be negative. However, the detection of exon 7 would be positive and the anti- $\mathrm{D}$ prophylaxis is appropriate. The molecular basis of the partial D phenotype DBT is the RHD-RHCE hybrid gene with rearranged exons 5-7 or 5-9 [29, 30]. NIPT results would be negative, but the DBT phenotype is characterized by the presence of $\mathrm{D}$ epitopes that can immunize a $\mathrm{D}$-negative mother. In such a case, the anti-D prophylaxis would be appropriate but would not be administered, because of the negative NIPT result for exons 5 and 7. However, DBT alleles $\left(R H D^{*} 14\right)$ are rare in Caucasian and other populations. The NIPT analysis of a third exon, i.e., $R H D$ exon 3 or exon 10, could further increase the safety of detection of $R H D$ variants, and assays for qPCR have been published [14, 19].

In addition to Y-chromosomal markers, anonymous autosomal SNPs have been considered and investigated as control markers to prove the presence of fetal cfDNA in maternal plasma [19]. Recent progress in this field has mainly been based on massive parallel sequencing in order to detect paternally inherited SNP alleles in maternal plasma $[31,32]$. We established and validated dPCR assays for three autosomal SNPs from the SNPforID panel [17] to demonstrate the feasibility of sensitive SNP typing from cfDNA. In $1 \%$ plasma mixtures, the targeted SNP alleles could be reliably detected. The assays showed very low backgrounds in the absence of the target allele. Our panel of dPCR assays will be extended to additional autosomal SNPs.

In summary, we were able to show the suitability of dPCR for NIPT of blood group and platelet antigens from cfDNA. For validation of dPCR, we predominantly used mixed plasma samples from volunteer donors and only a limited number of plasma samples from pregnant women. A clinical validation study has been initiated to determine the sensitivity and specificity of the assays, which is necessary before implementing NIPT in routine care. The risk of false-positive results or contamination has to be considered for this PCR method, especially because of preamplification. Therefore, in our standard protocol, we implemented the processing of control plasma (negative for RHD, KEL1, HPA-5b, and Y-chromosome) in parallel to the test samples. The work flow for routine diagnosis includes determination of the maternal genotypes for the requested targets and for the control SNPs from genomic DNA. Plasma cfDNA is then analyzed for the requested targets and the homozygous control SNPs using dPCR. Including plasma separation, cfDNA isolation, preamplification, and dPCR analysis, up to 5 test samples in addition to the control plasma can be analyzed each for 4 targets (e.g., $R H D$ exon 5, RHD exon 7, and 2 control SNPs; total: 6 samples on 24 chips) within a working day. We established a standardized and robust procedure that can be easily transferred to further NIPT targets. Automation of the chip-based APCR is desirable, but this is not possible with the current devices. Irrespective of the method used, the result of NIPT is uncertain if no target or control is positive. In such cases, the number of controls should be increased to prove the presence of reasonable amounts of cffDNA.

\section{Statement of Ethics}

This validation study was performed on blood samples from healthy volunteer donors (staff of the institute) after they had given their consent. The validated dPCR protocol was applied to plasma samples from pregnant women who also gave informed written consent. The study protocol was approved by the local ethics committee (Vote No. 2017-665N-MA).

\section{Disclosure Statement}

The authors declare no conflict of interest.

\section{References}

1 Müller SP, Bartels I, Stein W, Emons G, Gutensohn K, Köhler M, et al. The determination of the fetal D status from maternal plasma for decision making on $\mathrm{Rh}$ prophylaxis is feasible. Transfusion. 2008 Nov;48(11):2292301.

2 Lo YM, Bowell PJ, Selinger M, Mackenzie IZ, Chamberlain P, Gillmer MD, et al. Prenatal determination of fetal $\mathrm{RhD}$ status by analysis of peripheral blood of rhesus negative mothers. Lancet. 1993 May;341(8853):1147-8.

3 Clausen FB, Steffensen R, Christiansen M, Rudby M, Jakobsen MA, Jakobsen TR, et al. Routine noninvasive prenatal screening for fetal RHD in plasma of RhD-negative pregnant women -2 years of screening experience from Denmark. Prenat Diagn. 2014 Oct; 34(10):1000-5. 
4 de Haas M, Thurik FF, van der Ploeg CP, Veldhuisen B, Hirschberg H, Soussan AA, et al. Sensitivity of fetal RHD screening for safe guidance of targeted anti-D immunoglobulin prophylaxis: prospective cohort study of a nationwide programme in the Netherlands. BMJ. 2016 Nov;355:15789.

5 Haimila K, Sulin K, Kuosmanen M, Sareneva I, Korhonen A, Natunen S, et al. Targeted antenatal anti-D prophylaxis program for $\mathrm{RhD}$ negative pregnant women - outcome of the first two years of a national program in Finland. Acta Obstet Gynecol Scand. 2017 Oct: 96(10):1228-33.

6 Moise KJ. Fetal anemia due to non-Rhesus-D red-cell alloimmunization. Semin Fetal Neonatal Med. 2008 Aug;13(4):207-14.

7 Scheffer PG, van der Schoot CE, Page-Christiaens GC, de Haas M. Noninvasive fetal blood group genotyping of rhesus D, c, E and of K in alloimmunised pregnant women: evaluation of a 7-year clinical experience. BJOG. 2011 Oct;118(11):1340-8.

8 Rieneck K, Bak M, Jønson L, Clausen FB, Krog GR, Tommerup N, et al. Next-generation sequencing: proof of concept for antenatal prediction of the fetal Kell blood group phenotype from cell-free fetal DNA in maternal plasma. Transfusion. 2013 Nov;53(11 Suppl 2):2892-8.

9 Cro’ F, Lapucci C, Vicari E, Salsi G, Rizzo N, Farina A. An innovative test for non-invasive Kell genotyping on circulating fetal DNA by means of the allelic discrimination of $\mathrm{K} 1$ and K2 antigens. Am J Reprod Immunol. 2016 Dec;76(6):499-503.

10 Curtis BR, McFarland JG. Human platelet antigens - 2013. Vox Sang. 2014 Feb;106(2):93102 .

11 Scheffer PG, Ait Soussan A, Verhagen OJ, Page-Christiaens GC, Oepkes D, de Haas M, et al. Noninvasive fetal genotyping of human platelet antigen-1a. BJOG. 2011 Oct;118(11): 1392-5.

12 Wienzek-Lischka S, Krautwurst A, Fröhner V, Hackstein H, Gattenlöhner S, Bräuninger $\mathrm{A}$, et al. Noninvasive fetal genotyping of human platelet antigen-1a using targeted massively parallel sequencing. Transfusion. 2015 Jun;55(6 Pt 2):1538-44.
13 Orzińska A, Guz K, Uhrynowska M, Dębska M, Mikula M, Ostrowski J, et al. Noninvasive prenatal HPA-1 typing in HPA-1a negative pregnancies selected in the Polish PREVFNAIT screening program. Transfusion. 2018 Nov;58(11):2705-11.

14 Svobodová I, Pazourková E, Hořínek A, Novotná M, Calda P, Korabečná M. Performance of Droplet Digital PCR in Non-Invasive Fetal RHD Genotyping - Comparison with a Routine Real-Time PCR Based Approach. PLoS One. 2015 Nov; 10(11):e0142572.

15 Zhang BO, Xu CW, Shao Y, Wang HT, Wu YF, Song YY, et al. Comparison of droplet digital PCR and conventional quantitative PCR for measuring EGFR gene mutation. Exp Ther Med. 2015 Apr;9(4):1383-8.

16 Sullivan KM, Mannucci A, Kimpton CP, Gill $P$. A rapid and quantitative DNA sex test: fluorescence-based PCR analysis of X-Y homologous gene amelogenin. Biotechniques. 1993 Oct;15(4):636-8.

17 Sanchez JJ, Phillips C, Børsting C, Balogh K, Bogus M, Fondevila M, et al. A multiplex assay with 52 single nucleotide polymorphisms for human identification. Electrophoresis. 2006 May;27(9):1713-24.

18 Finning KM, Martin PG, Soothill PW, Avent ND. Prediction of fetal D status from maternal plasma: introduction of a new noninvasive fetal RHD genotyping service. Transfusion. 2002 Aug;42(8):1079-85.

19 Doescher A, Petershofen EK, Wagner FF, Schunter M, Müller TH. Evaluation of singlenucleotide polymorphisms as internal controls in prenatal diagnosis of fetal blood groups. Transfusion. 2013 Feb;53(2):353-62.

20 Portegys J, Rink G, Bloos P, Scharberg EA, Klüter H, Bugert P. Towards a Regional Registry of Extended Typed Blood Donors: Molecular Typing for Blood Group, Platelet and Granulocyte Antigens. Transfus Med Hemother. 2018 Oct;45(5):331-40.

21 Fazekas de St Groth S. The evaluation of limiting dilution assays. J Immunol Methods. 1982 Mar;49(2):R11-23.

22 Sillence KA, Roberts LA, Hollands HJ, Thompson HP, Kiernan M, Madgett TE, et al. Fetal Sex and RHD Genotyping with Digital PCR Demonstrates Greater Sensitivity than Real-time PCR. Clin Chem. 2015 Nov;61(11): 1399-407.
23 de Haas M, Finning K, Massey E, Roberts DJ. Anti-D prophylaxis: past, present and future. Transfus Med. 2014 Feb;24(1):1-7.

24 Saramago P, Yang H, Llewellyn A, Walker R, Harden M, Palmer S, et al. High-throughput non-invasive prenatal testing for fetal rhesus $\mathrm{D}$ status in $\mathrm{RhD}$-negative women not known to be sensitised to the RhD antigen: a systematic review and economic evaluation. Health Technol Assess. 2018 Mar;22(13):1-172.

25 Kent J, Farrell AM, Soothill P. Routine administration of anti-D: the ethical case for offering pregnant women fetal RHD genotyping and a review of policy and practice. BMC Pregnancy Childbirth. 2014 Feb;14(1):87.

26 Zwiers C, van der Bom JG, van Kamp IL, van Geloven N, Lopriore E, Smoleniec J, et al. Postponing early intrauterine transfusion with intravenous immunoglobulin treatment; the PETIT study on severe hemolytic disease of the fetus and newborn. Am J Obstet Gynecol. 2018 Sep;219(3):291.e1-9.

27 Daniels G. Variants of RhD - current testing and clinical consequences. Br J Haematol. 2013 May;161(4):461-70.

28 Sandler SG, Chen LN, Flegel WA. Serological weak D phenotypes: a review and guidance for interpreting the RhD blood type using the RHD genotype. Br J Haematol. 2017 Oct; 179(1):10-9.

29 Beckers EA, Faas BH, Simsek S, Overbeeke MA, van Rhenen DJ, Wallace $M$, et al. The genetic basis of a new partial $\mathrm{D}$ antigen: DDBT. Br J Haematol. 1996 Jun;93(3):720-7.

30 Huang CH, Chen Y, Reid ME, Okubo Y. Evidence for a separate genetic origin of the partial D phenotype DBT in a Japanese family. Transfusion. 1999 Nov-Dec;39(11-12):125965.

31 Qu N, Xie Y, Li H, Liang H, Lin S, Huang E, et al. Noninvasive prenatal paternity testing using targeted massively parallel sequencing. Transfusion. 2018 Jul;58(7):1792-9.

32 Yang D, Liang H, Lin S, Li Q, Ma X, Gao J, et al. An SNP panel for the analysis of paternally inherited alleles in maternal plasma using ion Torrent PGM. Int J Legal Med. 2018 Mar; 132(2):343-52. 